\title{
Viewpoint
}

\section{Health and psychological health in present time}

\author{
Sujeet Singh', Rajesh Kumar Singh², Rakhi Singh ${ }^{3}$ \\ 1 Shivpur, Varanasi, Uttar Pradesh, India, ${ }^{2}$ Centre of Experimental Medicine and Surgery, Institute of Medical Sciences, Banaras Hindu University, \\ Varanasi, India, ${ }^{3}$ Department of Library and Information Science, Mahatma Gandhi Kashi Vidyapith, Varanasi, India \\ Keywords: learning, instincts, thoughts, evolution and adaptation, psychological health
}

https://doi.org/10.29392/001c.12225

\section{Journal of Global Health Reports}

Vol. 4, 2020

\begin{abstract}
Just few centuries back our health concerns were more related to physical illness; a century back we had more concerns related to physiological health problems; since the last few decades we have more mental health concerns. But now with general observation, it seems we have more health concerns related to: emotions, motivations, feelings, imaginations, thoughts, etc.; well-being of all these may be categorized as "Psychological Health". Though in present scenario "Psychological Health" is a relatively negligible term; may be because it does not attract much commercial interests. But if we analyze, all our being is based on Psychological Health. Psychological Health is based on interaction of our biological system with the society and the nature. Biological aspects needs biological intervention, and social and nature interactions needs psychological intervention; hence interdisciplinary. Majority of the health issues like cancer, high blood pressure, diabetes, insomnia, depression, etc., has some link with Psychological Health. Quality sleep which is the basis of almost all health aspects has direct link with psychological health. Our behavior, relevancy and efficiency of our working, our comprehending ability, etc., are based on our Psychological Status. Thus we can say our happiness depends on Physiological Health; as better health, and better performance and good behavior, makes us happy and satisfied. We have explored in this article importance of Psychological Health, in context to overall health related to: thoughts, superiority, romance, learning, physical activity, etc; and for what interventions can be made, at both psychological and physical level. As our topic may interest even common individual, hence language has been purposely kept simple.
\end{abstract}

Since the last few decades our health expenditure is raising exponentially, with good achievement of higher life expectancy and survival rates. ${ }^{1-3}$ Meanwhile there is decline in general health of the population, as more people are getting health issues like: diabetes, blood pressure, heart diseases, cancer, digestion problem, insomnia, depression, hopelessness, emotional disorders, etc. ${ }^{4-7}$ Because recent medical intervention has focused on curing the ailments; neglecting correcting the cause of the ailments, and keeping blind-eye on developing internal health and psychological aspects. The scenario is something like "answering questions on student behalf, when student does not know answer of questions in the examination". When modern medical science is not used judiciously, it alters development of internal health mechanisms. The higher life expectancy for which we are happy today, may not last after few decades or we may have to live with inferior health. Because the people who are living longer today, had better internal health during their adulthood, as during their childhood and adolescent years, their body got better exposure to develop internal health; and modern medical science helped them happily live for longer time. But in present time, children and adults are many times unnecessarily assisted with modern medical intervention, and due to drastic change in lifestyle, development of internal health is affect- ed; hence this may result in decreasing life expectancy or inferior health, in future. ${ }^{4}$ As health expenditure is increasing exponentially and health issues are also increasing exponentially, 1,2,6 this clearly suggests that we are not moving in right direction in managing health issues. Though medical science has solved many big health issues successfully to a large extent like: measles, typhoid, polio, cholera, etc., which were life threatening, have done various surgery advancement, and are further making progress in solving some of the major health problems we are facing today; for which we should certainly be proud of.

Background of health issues is that, with the advent of Industrial Revolution, there has been tremendous change in lifestyle and social fabric. Such rapid changes were never witnessed in any evolutionary period, so there is unprecedented pressure to evolve and adapt, both physiologically and psychologically. ${ }^{4,8}$ This heavy pressure results fragile health, as our body has to adapt and evolve on many aspects. ${ }^{5,9,10}$ We have witnessed so much drastic and varieties of lifestyle changes in just last few decades, together with changes in the environment; to which we are unable to evolve and adapt or cope up. ${ }^{4}$ So a very large variety of newer health issues, both physiological and psychological, are popping up; with which current way of managing health issues is unable to keep pace. Because medical science can- 
not make human evolve and adapt according to this change. Further the situation is becoming alarming due to tremendous commercialization and fragmented efforts. ${ }^{11,12}$ Hence there is need for unified and genuine efforts to build general health of individuals, both at psychological level and physiological level. 13,14

Mechanisms of, each of our psychological aspects depends on many factors. At minute level unlimited combinations of workings of: subatomic particles, biomolecules, etc.; together with external factors like: social, environmental, etc., decide our various psychological aspects. So psychological aspects may not be as clearly described by few statements, definitions or words, as aspects are described in other field of science; but it can conveniently be categorized under various categories and explained with important points. Here in this article some of such categories are: thoughts, superiority, romance, laziness, emotions, learning, etc., wherein each word covers many aspects.

Undue stress is the major cause of deterioration of health. ${ }^{15,16}$ At psychological level in present era, we feel more stressed because of various reasons. Some of such major reasons are: unable to manage various types of thoughts, unable to manage our basic instinct of: showing superiority, expression of romance, laziness, ie, "though we want result but we do not want to labor", etc. All these issues have magnified due to rapid change in social fabric, lifestyle, etc., and the problem is further getting aggravated due to faulty learning techniques.

Many interventions are required to resolve all these and that cannot be scope of a single article, simultaneously for a single important topic, going through different sources becomes difficult. But there are some major aspects, of which some important points can be explored in an article; on which we can certainly work; which can tremendously reduce our unnecessary burden to evolve and adapt. Thus making health management easier, hence reducing heavy pressure on medical professionals, enabling them to work efficiently; such interventions are explored below.

\section{AT PSYCHOLOGICAL LEVEL}

\section{MANAGING OUR THOUGHTS}

Confusion, indecisiveness, unable to concentrate, struggling with unwanted thoughts, agitated mind, etc., has become general phenomenon. All these are engulfing our cognitive energy, making us less efficient; and we don't want thoughts which create such problems. We can categorize all such disturbing thoughts as negative thoughts, which includes intrusive thoughts. There has been many research on stopping some of such thoughts, which clearly established that such thoughts can't be stopped, and trying to do so had been counterproductive. ${ }^{17-19}$ Further many studies have confirmed that understanding and ignoring such thoughts with: reasoning, understanding and conditioning, is the best approach in dealing with unwanted thoughts. $20-22$

Thoughts relates to creativity, imagination, memory, etc. Good Brain means: Better Creativity, Better Imagination, Better Memory, etc. If our brain is creative then we will try to create new things, both good (positive) and bad (nega- tive); it's not possible for our brain to have only good creativity. If we are imaginative, we will imagine both good and bad things; it's not possible to imagine only good things. Similarly if we have good memory we will remember both good and bad things; it's not possible to remember only good things, etc. ${ }^{23-25}$ This means our thoughts remains wandering or fluctuating between extremes of positives and negatives; hence we are bound to get disturbed due to this wandering or fluctuations. It makes us puzzled, confused and leads us to indecisiveness. Impact of this wandering and fluctuation, of various thoughts results in clashes of thoughts, mental disturbances and frustration; leading to many psychiatric disorders, making people take shelter under psychiatric medicines, or succumbing to addiction. ${ }^{26}$ But medicines cannot be a permanent solution, and they cannot make brain to work only positively. Medicines are only for emergency or for taking out patient form psychiatric lows or temporary solution or for support; understanding with reasoning is the only permanent solution.

Fact is that we are scared of negative working of our brain and wish to get rid of it. We have developed a perception that if we do not have negative thoughts, we would do great. So we try to eliminate negative working of our brain; but that cannot be achieved. $17,18,21$ We must understand that negative brain workings cannot be stopped alone without stopping positives. Can anybody tell lie without knowing the truth! No, similarly one cannot tell truth without knowing the lie, ie, if there is no lie there is no truth; this means if there is no negativity, there cannot be any positivity. In fact what types of positivity we have depends on what types of negativity we have; correct negativity gives positivity a correct direction. ${ }^{27-32}$ And whatever goes in our mind has some context/reference, without context or reference no thought can come to our mind; understanding that context is important to understand our thoughts, and that context must be correct to enable good working. Even our DNA has two strands and each work as complimentary, further RNA transcription and protein formation are also complementary; and their functioning is mainly based on orientation of functional groups in anti-direction.

We do blunder in trying to suppress or stop negatives; if we only suppress negative then particular negative becomes even stronger, as it gets more reinforced ${ }^{19}$ due to more attention; whereas if all thoughts are suppressed then positives also are suppressed, hence reducing our performance. The situation now is that we are even scared of free thinking and wish to suppress or stop thoughts; instead we should try to think as free as we can, without much condition. Our thoughts decide our performance, so it should not be suppressed. 33 The only thing required is to understand with reasoning, negative and positive thoughts, so as to be able to identify negative thoughts. So that we can ignore negative thoughts and implement positive thought, though negatives will always be there in the background ${ }^{20}$; just like we frequently reminds ourselves that we should not do wrong things, although we know many wrong things. This will allow us of free thinking and thus will enhance our performance.

Considering the whole scenario, we realize that we have various types of thoughts, which can be said to be whole gamut of thoughts. Wherein each type or category of 
thoughts like: thoughts related to romance, thought related to responsibility, etc., can be said to be separate spectrum of thoughts; ie, spectrum of thoughts related to romance is one spectrum, spectrum of thoughts related to responsibility is another spectrum. Whole gamut of thoughts is necessary as each thought complement or helps other; wherein each thought to be used is: referenced, compared, weighted, or combined, with other relevant thoughts. If the necessary thought for reference or comparison, etc., is not there or wrong, then our thought becomes irrelevant or wrong. 34

Now the gamut of thoughts must be in a healthy range. If the gamut of thoughts is severely dominated by few disturbing thoughts, then it must be corrected by exposure, reasoning and understanding, ie, counseling. Our various thoughts depends on our experience, understanding, knowledge, information, working, genes, etc. So if any one or more of this gets wrong then the gamut of thoughts gets unhealthy, leading to inefficient or irrelevant or wrong works. Hence we should always try to get better experience, understanding, knowledge, information, working, etc., to have correct thought generation.

Here we need to understand that each individual is different, because of different social interaction, genes, etc.; so their thinking inclination and direction will also be different. When the thinking inclination is too different and is not understood well it leads to psychiatric disorders. But if it's understood, it leads to creation by the effected person. Like in the case of Obsessive-Compulsive Disorder (OCD) sufferers, their thoughts are abnormally inclined to various risks. But if they are trained to understand that some of the risks are irrelevant, some are just imaginary and some are part of our life, and we can control some of the risks but not all. Then they will give attention on relevant risks only and ignore all others; though it needs intense counseling. $20-22,31,35$ This will make them relaxed and hence enable them to work on real or relevant risks, resulting in better risk management works; which can benefit others also, hence new creations. As earlier their brain was abnormally inclined to risk, so earlier it was psychiatric problem; but now due to understanding and counseling, it is creation. Similar is the case with many other psychiatric disorders. ${ }^{36}$

In order to achieve above objective, we have to correct basics of living. With correct working, experience, understanding and knowledge, we will have correct thoughts, and we can identify and ignore negative thoughts. This will make our workings important and efficient, leading to peaceful and pleasant living with better performance.

\section{MANAGING OUR INSTINCTS}

Many of our problems are because of our various instincts like: Showing Superiority or Establishing Dominance, Romance, Laziness, etc. Many times we hide, suppress or not correctly express these instincts. But if we understand why we have these instincts, what is the meaning of these instincts; then we will not unnecessarily inhibit or suppress these instincts. Heavy suppression or inhibition leads to wrong bursts or vent out of these instincts, loss of motivation and interest, and deterioration of psychological health. Whereas better understanding of our instincts, enable us for better utilization of instincts; leading to efficiency, calmness, quality sleep and happiness. Below is the brief exploration of some of our major instincts.

\section{SUPERIORITY}

In general people show superiority with their class, race, religion, nationality, etc.; and with power, luxury, materialistic things, etc. ${ }^{37-44}$ We have witnessed so many wars, clashes, frictions, etc., due to showing of these indifference, and further such disputes is going on; even personal relations in family, friends, etc., many times gets disturbed due to wrong expression of superiority. During evolutionary period, this instinct was more related to establishing dominance. All this results huge wastage of resources, and hampers peace and health. It has been proved clearly by various studies that humans have self favoring bias, and this creates indifferences and frictions; when in group the group also self favors. Hence this human nature is also responsible for creating differences. ${ }^{39,45-47}$

This human tendency has helped them in evolution in early phases but in later phases of evolution, human wisdom helped them to perform better than animals. Most of our behavior depends on our DNA and human DNA resembles to that of animals especially chimpanzee, to a very large extent. This means we will have some of the traits of animals. But as humans have developed more compared to other animals, mainly because of wisdom; hence we should use our wisdom primarily over other traits like power, class, etc. ${ }^{47-50, S 51-S 53}$ That is we should show superiority primarily with our wisdom, which includes justice. We should understand that if we could not show/express our this instinct in correct way, then this instinct is bound to get vent in inferior or wrong way. ${ }^{554}$ Hence we should express superiority primarily by our wisdom, otherwise it may find other outlet, ie, class, race, religion, nationality, etc., and with power, luxury, etc.

Our instinct of showing superiority, motivates us to improve 41,42,S55,S56; and as discussed above our wisdom enables us for real progress, which comprises good works; this is also supported by our exploration about thoughts. We feel much happy and satisfied, when our superiority is expressed more by our good works, rather than by power, luxury, class, nationality, etc. Alfred Adler in his study found that if a person does not feel strong enough to compete with other in useful terms, then he/she tries to show superiority in other useless terms. This means if our education system is such that an individual knows where to show his worth and how to do it, then it will reduce unnecessary and wrong expression of superiority. S54

\section{ROMANCE}

Whatever traits and tastes we have, are in general beneficial for our survival and progress. Like whatever food we like (other than the newer foods to which we have not been evolved through) eg, fruits, dry fruits, non-vegetarian or diary foods, etc., are good for health, with respect to earlier lifestyle; though in present changed lifestyle they may not be healthy. Our inherent nature of hospitality and empathy, is beneficial for collective social development. ${ }^{\mathrm{S} 57}$ We like greenery as such places are more habitable. In the same way 
most of the features of romance are beneficial for our survival, progress and better living. One gets attracted to opposite sex due to "color, shapes, behavior, emotions, etc.", though criteria of these features depend on an individual, society and habitat suitability; each of these features are helpful for producing better offspring, better living and progress. Whatever is needed to produce better offspring, we have very strong inclination for that; for some details open references as cited. $\mathrm{S} 58, \mathrm{~S} 59, \mathrm{~S} 68-\mathrm{S} 71, \mathrm{~S} 60-\mathrm{S} 67$ This instinct is so strong that most of our entertainment channels like: songs, films, etc., are dominated by various features of romance like: love, dedication, commitment, etc.

As in the above discussion, understanding and expression, enables better benefit of this instinct. Lack of understanding and suppression of this instinct, results in wrong outlet or bursts, causing immoral and unsocial acts. We have features to inhibit or suppress, some of our feelings and instinct. When the desired inhibition or suppression is within limit then it is easily complied; but when it exceeds, it bursts or vent out in any possible way. ${ }^{572}$ Liberal society with good knowledge and understanding, with minimum but efficient social rules had always progressed well historically; as social rules are easily complied with. This instinct enables us to give our best, whereas unnecessary suppression of this instinct prevents such motivation.

\section{LAZINESS AND HOW INSTINCT WORKS TOGETHER}

The above two instinct "Superiority and Romance" very strongly motivates us to do better work and this instinct "Laziness", helps in organizing our work, or do work on priority basis $34, \mathrm{S73}$; when these three instincts are in balance and work in co-ordination, they enable efficient and better work, with good living. Likewise most instinct complements each other. Laziness instinct helped in evolutionary period, in preventing wastage of energy, hence enhancing chances of survival.

\section{OTHER PSYCHOLOGICAL ASPECTS}

\section{EMOTIONS}

There is a general perception that anger is bad and we should control it; it's the perfect case, where an important emotion is getting bad name. When anger is suppressed, it results anger vent out or burst in wrong way, and lead to health and other problems. ${ }^{\mathrm{S} 74}$ It is a very beneficial emotion; if we are psychologically healthy then anger gets expressed at correct points, like when something gets wrong, then one gets angry, enabling correction of wrong things. If we don't get angry at correct point then we are not psychologically healthy and have wrong psychological status. Likewise the case is with laughter and many other emotions. S75-S77

\section{LEARNING}

To understand or comprehend other's experience, one should have at least relevant basic experience; and be in matching psychological status. Academic literature, which can be said to be accumulated abstract of, experiences of individuals or societies; hence needs learner's relevant basic experience, to study and comprehend it. So real learning is based on some basic experience and psychological status, of the individual. Without relevant basic experience of individual, even if he/she studies academic literature, they can't bring any positive result with that knowledge. ${ }^{\text {S78 }}$

Learning is the basis for any development or progress, and learning techniques make a vast difference, in acquiring quality knowledge. In all our evolutionary period we have been learning through experience and observation, so we have developed features of learning through experience and observation. So it would be meaningful if learning is initiated with experience, observation or practical. A child efficiently learns mother language and many things by observation and interaction, with least effort and without formal education; so learning based on such aspects like: observation, interaction, etc., will be much easier and useful. S79,S80,S89,S81-S88 We are blessed that we are living in digitalized era, wherein specific updated information or study matter, could be very easily accessed through internet. Hence there should be minimal memorization based study; extensive memorization could be left to specialized field. This reduces unnecessary pressure of learning, enabling leftover cognitive energy for better knowledge and better concepts.

As one should have basic knowledge of, most of all relevant subjects like: science, math, psychology, social study, history, etc., for better rational thinking; which is the basis of better understanding and correct decisions; so basic study should incorporate, basic fundamental concepts of all these subjects. In-depth learning, rigorous practice, memorization, etc., should be left over to specialized study.

\section{AT PHYSICAL LEVEL}

\section{PHYSICAL ACTIVITY}

In all our evolutionary period we have been going through a lot of physical activity, abruptly lowering it will make our body difficult to adapt and evolve, and hence may result health problems. ${ }^{4}$ So our living style should be such that it incorporates some basic physical activity, as far as pos-

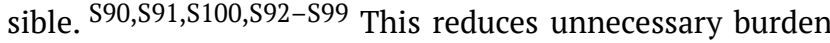
for exercise, yoga, etc., to keep us healthy. It saves our time, prevents wastage of physical energy, reduces disturbing concern to remain healthy, involves healthy movements of body parts, $\mathrm{S} 101$ enable better blood circulation, gives us important experiences, etc.; hence prevents wastage of resource and enhances our experience. Physical activity only to keep healthy, most of the time is not continued in longer run, as they are not enjoying, just like: learning without curiosity, eating food without hunger/taste, etc.; but when it is incorporated in daily working, it can be easily complied. In our evolutionary period also physical activity was involved to fulfill various desire/needs, so for better compliance physical activity should be incorporated in daily routines, as far as possible.

Vitamin D deficiency which is becoming a worldwide phenomenon, causes bone problems, inferior sleep, cancer, etc.; and may be culprit of other health problems that we presently don't know. $\mathrm{S102-S108}$ We know that sun exposure helps us make precious vitamin $\mathrm{D}$, but there may be many 
other benefits to normal exposure to sunlight, that we may not be knowing S109,S110; and normal exercise done in morning or indoor, does not give sufficient vitamin D, though it is beneficial in some other aspects. Alternately we may think that we can take vitamin D supplement, but the biological systems engaged with production of Vitamin $\mathrm{D}$, when left less functional, may malfunction also. Similar is the case with some other nutrients; physical activity enhances absorption of nutrients in a balanced manner and also helps clear toxins from our body, ${ }^{\mathrm{S} 111}$ further physical activity improves sleep, immunity, cognitive functions, gene expression, protects DNA, etc. Altogether this means normal physical activity protects and improves many biological mechanisms. ${ }^{4, S 120-S 124, S 112-S 119}$

Further there are many disorder related to lower water intake like: kidney stones, constipation, etc.; directly increasing water intake is the general practice to counter such problems. ${ }^{\mathrm{S} 125-\mathrm{S} 128}$ Here we should also see that why we are not drinking enough water, it may be because we may not be doing enough physical activity to feel sufficiently thirsty or in good psychological health, which enable good thirst mechanism; and this may be signal that our internal system is not balanced. ${ }^{5129-S 133}$ In general a healthy person doing normal physical activity, will automatically drink sufficient water because of feeling thirsty, to meet his/her body requirement. ${ }^{S 134}$ Drinking water when thirsty has wider benefits than drinking water without feeling thirsty. Hence it's much better to incorporate some basic physical activity in daily routine which fulfill a wider range of requirements by exposing us to various aspects as explored above, thus reducing our unnecessary burden and increases our efficiency. $S 93$

\section{WORKING}

We are blessed that we are living in a mechanized and digitalized era, wherein we have various machines to assist in our works. And our working should be mechanized as much as possible; mainly leaving works that cannot be done by machines and digital media, to ourselves like: intellectual or creative works; ie, intellectual and creative work should primarily be done by us. Though needed physical work should be left for individuals for fulfilling his/her health requirements. Where ever there is regular repetitive type of work is involved, for example: in teaching, in professional working, etc., mechanization should be done; to avoid wastage of intellectual resources.

Secondly in our working we see that there should be no mistake, ensuring it consumes lots of cognitive ener-

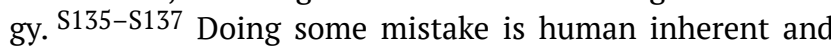
beneficial character, as it helps in remaining creative; even DNA transcription and replication does some mistakes and that mechanism has been beneficial, especially for evolution. ${ }^{S 138, S 139}$ Forcing to stop mistakes will kill creativity. So were we cannot tolerate mistakes, machines should be used for such tasks with other required management. $\mathrm{S} 140, \mathrm{~S} 141$

\section{SLEEP}

Sleep plays basic restorative and developmental role, in many psychological and physiological aspects; quality sleep is prime requirement of overall health. ${ }^{S 142}$ Insomnia which is becoming a worldwide predominant phenomenon is basically reflection of some underlying health problems, which must be addressed to have quality sleep. Inducing good sleep is part of many treatments, especially for psychiatric cases. Sleeping outside the recommended range, in most cases, is the signal of some health issues. ${ }^{\mathrm{S} 143, \mathrm{~S} 144}$

Quality sleep depends on psychological status, nutrient and hormonal balance, physical activity, etc., and vice versa. $\mathrm{S} 113, \mathrm{~S} 124, \mathrm{~S} 145-\mathrm{S} 150$

\section{EVOLUTION AND ADAPTATION}

Whatever traits or features, we have, using that for our benefit and progress is easier and beneficial; enhancement of such features or evolution, is also easier. Whereas traits or features, which is weaker or dormant or we don't have; working on those traits or features, is very difficult and may be of less benefit; evolution of such traits is also difficult. ${ }^{S 151}$ Hence most of the time it's much beneficial to use traits or features, we have got through evolution.

Historically we have been going through slow process of evolution and adaptation. When the desired adaptations or evolutions, were drastic or rapid, due to rapid change in habitat or ecosystem, many time it led to extinction of various species. ${ }^{S 152, \mathrm{~S} 153}$ If there are varieties of adaptive and evolutionary pressure, as we see in present era, due to rapid change in lifestyle, social fabric and environment, then it gets difficult for our body to manage these requirements. As our body has to evolve and adapt at many front and so lead to fragile health. $\mathrm{S149, \textrm {S } 1 5 4}$ Whereas if there are few adaptive or evolutionary requirement, as has been happening in our past evolutionary period, then it becomes easier for our body to deal with those requirements.

We take care of health issues when our body gives some signal, but it may be possible that some health problems may not be giving any signal, and harming our physiological and psychological aspects. Most of the known health issues that we know, when studied revealed, are mainly because of rapid change in lifestyle, ${ }^{9}$ social fabric and environmental changes; so it may be that many of health issues with which we are not aware of or have not been studied yet, may also be related to rapid change in lifestyle, social fabric and environment. ${ }^{4}$ Hence considering all, it may be of great benefit if we could reduce unnecessary burden for evolution and adaptation, as explored in above sections. So that our body can concentrate on important evolution and adaptations; and for environment suitable steps should be taken. Rapid change in lifestyle and social fabric could be done in some aspects, if it is clearly understood, not to be comparatively harmful. Further we should work on reducing health hazards that has been clearly proved to be harmful like: pollution, unhealthy social life, unhealthy foods, etc. $\$ 155-\mathrm{S} 162$

\section{PSYCHOLOGY AND OTHER FIELD OF SCIENCE}

Getting psychological interests needs more interaction with society and environment, as compared to other field of science. Hence getting interest in psychology takes more time 
than interest in other field is generated, so initially students prefer other subjects more than psychology. By the time people get enough interaction with society, environment, etc., and get interested in psychology, many times they are busy with their professional life and have to shoulder family responsibility; so left with less energy and time to devote in psychology. Hence psychology is not sufficiently integrated with other academic field or discipline; as even comprehending ability for academic subjects or anything, depends on psychological status of the individual. To counter this, suitable measure could be taken like: teaching basic psychology in early years in schools, giving proper platform for those who have important idea or problem or solution.

\section{DISCUSSION}

Affluent societies are considered as milestone for progress, we want to become more and more affluent, and affluency is considered as path of progress. We can say financial achievement has become hallmark of progress. We should understand that unnecessary accumulation of wealth and primarily working for wealth and luxury is wastage of resources, both intellectual and physical; which could have been used for other better purposes. Health which is the basis of efficient and relevant working, comprehending ability, and happiness, should be the prime criteria of progress. Here we see that affluent society is predominantly suffering from health problems like: insomnia, anxiety, emotional distress, cancer, diabetes, high blood pressure, etc. Though their health issues are different from poorer society, where health issues are majorly: malnutrition, typhoid, malaria, etc. Here we see that both societies suffer from various health problems, but their health issues are different. This means in the making of affluent society some health issues got resolved but another set of health issues have crept in. ${ }^{\mathrm{S} 163}$ The health progress where some problem is solved, and newer creeps in, is not the real progress; the real health progress would have been where all set of health issues gets reduced. ${ }^{\mathrm{S} 164}$ We have explored in this paper, how we can work to protect and build internal health, at both psychological and physiological level, and improve our performance; hence satisfaction and happiness. But as we have explored health from a different but important perspective, so there is scope for further study and research.

As explored above under section "Managing Our Thoughts" in case of: indecisiveness, confusions, frustrations, etc., that is problem relating to "thoughts"; understanding thoughts and ignoring negative thoughts, and practicing it, is the better approach than suppressing thoughts. Likewise our exploration for various instincts like: Superiority, Romance, Laziness, etc., reveals that better understanding and expression, with minimal inhibition, together with all-around balanced instincts working together, gives better result. Like Superiority and Romance instinct, strongly motivates one, to work better; and together with laziness instinct, individual work better in an organized way. In case of emotion, if we have good psychological health, then emotions get expressed at correct points or occasion, which leads to beneficial effects.

In the case of learning which is based on observation, interaction, practical and practice, give better result, then learning based on memorization. In case of working, intellectual and creative works, should primarily be done by human; and repetitive and labor oriented works should be mechanized, as far as possible. In case of physical exercise, as far as possible some basic physical activity should be incorporated in daily routines.

We are going through tremendous change in lifestyle, social fabric and environment, which has resulted heavy pressure on our body to evolve and adapt, making our health fragile ${ }^{4}$; and as explored above, reducing unnecessary burden will enable our body to evolve and adapt on important aspects. This will make our health robust, working efficient and relevant, and life pleasing. Taking all together, in broader aspect, whatever evolutionary traits we have, using those for our development, is beneficial; and the traits that have helped us develop more than animals like: wisdom, better social life, etc., primarily using that for our development, should be of greater value. ${ }^{\text {S165,S166 }}$

\section{CONCLUSIONS}

Good health depends on many factors, many we know and many we don't know. The criteria that we know for good health are many, like: quality sleep, low stress, physical activity, balanced diet, psychological status, etc., and keeping vigilance of all is very difficult and annoying. As explored above, to keep ourselves healthy, we should not change drastically from earlier lifestyle, unless it's proved sufficiently that change is not comparatively dangerous. This will even prevent from unknown health issues to a large extent; as most of the health problems when studied revealed, are because of defective lifestyle, so many health issues with which we are not aware of, may be also because of defective lifestyle. As our biological clock is more balanced to earlier lifestyle, so sticking to it at the basic level will reduce tremendous pressure, to keep our internal system balanced to a major extent. The only thing extra required is to keep ourself vigilant that our lifestyle, which includes psychological and physical aspects as explored above, does not become abnormally imbalanced. Though all these seems complicated but like driving vehicle, especially riding bicycle, while learning it needs lots of attention and effort, but when have sufficient experience it becomes much effortless; to a lot extent the same is true in managing lifestyle. And as explored above, perhaps time has come to accept psychological health, as important part of overall health; as even comprehending ability of an individual also depends on psychological status of the individual.

Until just few century back, our progress were majorly based on evolution; wherein there was always danger of extinction. But as now we have good knowledge, and as explored above about some of the important aspects of our living, we can improve our internal health, working efficiency and relevancy, and comprehending ability, hence satisfaction and happiness; and further we can certainly take some important decision, to protect ourselves from many dangers and counter many dangers. 
Acknowledgements: The authors appreciate Dr. Anjan Trivedi (AFMC Pune, India) for his suggestions on technical aspects.

\section{Funding: None.}

Authorship contributions: Conceptualization by SS and RS; and written by SS, RKS and RS.

Competing interests: The authors have completed the Unified Competing Interest form at www.icmje.org/coi disclosure.pdf (available on request from the corresponding au- thor) and declare no competing interests.

\section{Correspondence to:}

Dr Rakhi Singh

114- Rudra Apartment

Near Shivpur Thana

Shivpur, Varanasi- 221003

India

rslib@rediffmail.com

References from 51 to 166 in the online supplementary material (S51 to S166) 


\section{REFERENCES}

1. OECD. Health expenditure and financing. https://st ats.oecd.org/Index.aspx?DataSetCode=SHA. Accessed September 6, 2019.

2. OECD. Health resources- Health spending. http s://data.oecd.org/healthres/health-spending.htm. Accessed September 8, 2019.

3. Life expectancy; top two graph. https://en.wikipedi a.org/wiki/Life_expectancy. Accessed September 6, 2019.

4. Carraro E, Schilirò T, Biorci F, et al. Physical Activity, lifestyle factors and oxidative stress in middle age healthy subjects. Int J Environ Res Public Health. 2018;15:E1152. doi:10.3390/ijerph15061152

5. Farhud DD. Impact of lifestyle on health. Iran J Public Health. 2015;44:1442-1444.

6. van Oostrom SH, Gijsen R, Stirbu I, et al. Time trends in prevalence of chronic diseases and multimorbidity not only due to aging: Data from general practices and health surveys. PLoS One. 2016;11:e0160264. doi:10.1371/journal.pone.0160264

7. Pappachan MJ. Increasing prevalence of lifestyle diseases: High time for action. Indian J Med Res. 2011;134:143-145.

8. World Health Organization. The determinants of health. https://www.who.int/hia/evidence/doh/en/. Accessed September 6, 2019.

9. Monteiro J. Will diet and exercise save us all? Cell. 2016;167:1431. doi:10.1016/i.cell.2016.11.027

10. Takeshita T, Morimoto K. Effects of lifestyle on health status. Rinsho Byori. 1995;43:1087-1194.

11. Brock DW, Buchanan AE. The profit motive in medicine. J Med Philos. 1987;12:1-35. doi:10.1093/im $\mathrm{p} / 12.1 .1$

12. Relman AS. The new medical-industrial complex. N Engl J Med. 1980;303:963-970. doi:10.1056/nejm19 $\underline{8010233031703}$

13. Jadad AR. Creating a pandemic of health: What is the role of digital technologies? J Public Health Policy. 2016;37(Suppl 2):260-268. doi:10.1057/s4127 1-016-0016-1

14. Ryff CD, Keyes CL. The structure of psychological well-being revisited. J Pers Soc Psychol. 1995;69:719-727. doi:10.1037/0022-3514.69.4.719
15. McEwen BS. Protective and damaging effects of stress mediators: Central role of the brain. Dialogues Clin Neurosci. 2006;8:367-381.

16. Segerstrom SC, Miller GE. Psychological Stress and the Human Immune System: A Meta-Analytic Study of 30 Years of Inquiry. Psychol Bull. 2004;130:601-630. doi:10.1037/0033-2909.130.4.601

17. Geraerts E, Merckelbach H, Jelicic M, Smeets E. Long term consequences of suppression of intrusive anxious thoughts and repressive coping. Behav Res Ther. 2006;44:1451-1460. doi:10.1016/j.brat.2005.1 $\underline{1.001}$

18. Kröner-Borowik T, Gosch S, Hansen K, Borowik B, Schredl M, Steil R. The effects of suppressing intrusive thoughts on dream content, dream distress and psychological parameters. J Sleep Res. 2013;22:600-604. doi:10.1111/isr.12058

19. Tolin DF, Abramowitz JS, Przeworski A, Foa EB. Thought suppression in obsessive-compulsive disorder. Behav Res Ther. 2002;40:1255-1274. doi:1 0.1016/s0005-7967(01)00095-x

20. Marcks BA, Woods DW. A comparison of thought suppression to an acceptance-based technique in the management of personal intrusive thoughts: A controlled evaluation. Behav Res Ther. 2005;43:433-445. doi:10.1016/j.brat.2004.03.005

21. Najmi S, Riemann BC, Wegner DM. Managing unwanted intrusive thoughts in obsessive-compulsive disorder: Relative effectiveness of suppression, focused distraction, and acceptance. Behav Res Ther. 2009;47:494-503. doi:10.1016/j.brat.2009.02.015

22. Wegner DM. Setting free the bears: Escape from thought suppression. Am Psychol. 2011;66:671-680. d oi:10.1037/a0024985

23. Dias FV, Oliveira RV, Leal I, Maroco J. Positive and negative thoughts in ambiguous anxiety - related stories: The child's perspective. Psychol Community Health. 2015;4:53-64. doi:10.5964/pch.v4i1.114

24. Simonton DK. The Mad-genius paradox: Can creative people be more mentally healthy but highly creative people more mentally ill? Perspect Psychol Sci. 2014;9:470-480. doi:10.1177/1745691614543973

25. Sweeny K, Shepperd JA. The costs of optimism and the benefits of pessimism. Emotion. 2010;10:750-753. doi:10.1037/a0019016 
26. Post F. Creativity and psychopathology. A study of 291 world-famous men. Br J Psychiatry. 1994;165:22-34. doi:10.1192/bjp.165.1.22

27. Alloy LB, Abramson LY. Judgment of contingency in depressed and nondepressed students: Sadder but wiser? J Exp Psychol Gen. 1979;108:441-485. doi:10.1 037/0096-3445.108.4.441

28. Adler SE, Delorenzo C. The Power of Negative Thinking. 2018. https://www.theatlantic.com/magazi ne/archive/2018/01/the-power-of-negativity/546560/. Accessed September 6, 2019.

29. George JM, Zhou J. Understanding when bad moods foster creativity and good ones don't: The role of context and clarity of feelings. Journal of Applied Psychology. 2002;87:687-697. doi:10.1037/0021-901 0.87.4.687

30. Koch AS, Forgas JP, Matovic D. Can negative mood improve your conversation? Affective influences on conforming to Grice's communication norms. Eur J Soc Psychol. 2013;43:326-334. doi:10.1002/ejsp.1950

31. Norem JK, Cantor N. Defensive pessimism: Harnessing anxiety as motivation. J Pers Soc Psychol. 1986;51:1208-1217. doi:10.1037/0022-3514.51.6.1208

32. Norem JK, Chang EC. The positive psychology of negative thinking. J Clin Psychol. 2002;58:993-1001. doi:10.1002/jclp.10094

33. Waddell C. Creativity and mental illness : Is there a link? . Can J Psychiatry. 1998;43:166-172. doi:10.117 7/070674379804300206

34. Smallwood J, Ruby FJM, Singer T. Letting go of the present: Mind-wandering is associated with reduced delay discounting. Conscious Cogn. 2013;22:1-7. do i:10.1016/j.concog.2012.10.007

35. Osgood-hynes. Thinking Bad Thoughts. https://do cplayer.net/20942934-Thinking-bad-thoughts.html. Accessed September 6, 2019.

36. Boulougouris JC, Marks IM. Implosion (flooding) - a new treatment for phobias. BMJ. 1969;2:721-723. doi:10.1136/bmj.2.5659.721

37. Ayim-aboagye D, Gyekye KA, Adzika V. Fundamental theorem of the theory of superiority complex. International Journal of Emerging Trends in Science and Technology. 2018;05-07/6688-6703.

38. Duriez B, Van Hiel A. The march of modern fascism. A comparison of social dominance orientation and authoritarianism. Pers Individ Dif. 2002;32:1199-1213. doi:10.1016/s0191-8869(01)0008 $\underline{6-1}$
39. Eisenegger C, Haushofer J, Fehr E. The role of testosterone in social interaction. Trends Cogn Sci. 2011;15:263-271. doi:10.1016/i.tics.2011.04.008

40. Levin S, Federico CM, Sidanius J, Rabinowitz JL. Social dominance orientation and intergroup bias: The legitimation of favoritism for high-status groups. Pers Soc Psychol Bull. 2002;28:144-157. doi:10.1177/0 146167202282002

41. Hoorens V. Self-favoring biases, self-presentation, and the self-other asymmetry in social comparison. $J$ Pers. 1995;63:793-817. doi:10.1111/j.1467-6494.199 5.tb00317.x

42. Hoorens V. Self-enhancement and Superiority Biases in Social Comparison. Eur Rev Soc Psychol. 1993;4:113-139. doi:10.1080/14792779343000040

43. Pratto F, Sidanius J, Stallworth LM, Malle BF. Social dominance orientation: A personality variable predicting social and political attitudes. J Pers Soc Psychol. 1994;67:741-763. doi:10.1037/0022-3514.6 $\underline{7.4 .741}$

44. Sidanius J, Devereux E, Pratto F. A Comparison of symbolic racism theory and social dominance theory as explanations for racial policy attitudes. J Soc Psychol. 1992;132:377-395. doi:10.1080/00224545.19 $\underline{92.9924713}$

45. Dorrough AR, Glöckner A, Hellmann DM, Ebert I. The development of ingroup favoritism in repeated social dilemmas. Front Psychol. 2015;6:476. doi:10.33 89/fpsyg.2015.00476

46. Wang X, Zheng L, Li L, et al. Immune to Situation: The Self-Serving Bias in Unambiguous Contexts. Front Psychol. 2017;8:822. doi:10.3389/fpsyg.2017.00 $\underline{822}$

47. Everett JAC, Faber NS, Crockett M. Preferences and beliefs in ingroup favoritism. Front Behav Neurosci. 2015;9:15. doi:10.3389/fnbeh.2015.00015

48. Grossmann I. Wisdom in context. Perspect Psychol Sci. 2017;12:233-257. doi:10.1177/174569161 $\underline{6672066}$

49. Grossmann I. Wisdom and how to cultivate it: Review of emerging evidence for a constructivist model of wise thinking. Eur Psychol. 2017;22:233-246. doi:10.1027/1016-9040/a000302

50. Grossmann I, Brienza JP, Bobocel DR. Wise deliberation sustains cooperation. Nat Hum Behav. 2017;1:61. doi:10.1038/s41562-017-0061 


\section{SUPPLEMENTARY MATERIALS}

\section{Online Supplementary Material}

Download: https://www.joghr.org/article/12225-health-and-psychological-health-in-present-time/attachment/ 31118.docx 